\title{
ИССЛЕДОВАНИЕ ФАКТОРОВ, ОКАЗЫВАЮЩИХ ВЛИЯНИЕ НА ЭФФЕКТИВНОСТЬ ДЕЯТЕЛЬНОСТИ КОММЕРЧЕСКИХ БАНКОВ В РОССИИ
}

\section{(C) 2021 Петров Александр Михайлович}

Департамент бизнес-аналитики, профессор, доктор экономических наук, доцент Финансовый университет при правительстве Российской Федерации, Россия, Москва E-mail: ampetrov@fa.ru

\section{(C) 2021 Цыпин Александр Павлович}

Департамент бизнес-аналитики, доцент, кандидат экономических наук, доцент Финансовый университет при правительстве Российской Федерации, Россия, Москва

E-mail: aptsypin@fa.ru

\section{(c) 2021 Фаизова Лилия Радиковна}

Кафедра статистики и эконометрики, доцент, кандидат экономических наук, доцент Оренбургский государственный университет, Россия, Оренбург

E-mail: faizova1980@list.ru

Банковская система является системообразующим сектором экономики России, от ее развитости и эффективности функционирования зависит наполнение экономической системы кредитами и как следствие поступательное развитие регионов страны. В этой связи считаем актуальным тему количественной оценки и качественной интерпретации влияния факторов на прибыльность региональной банковской системы. Целью написания статьи является оценка влияния внутренних факторов на вариацию эффективности деятельности кредитных организаций России на основе применения статистического инструментария. Для достижения поставленной цели, наряду с такими общенаучными методами как сравнение и анализ, были использованы математико-статистические методы: графический, табличный, корреляционно-регрессионный, многомерной группировки. В ходе выполнения исследования были получены следующие основные результаты: в России наблюдается снижение численности кредитных организаций, начиная с середины 1990-х годов, что обусловлено высокой конкуренцией на рынке капиталов и ужесточением надзора со стороны Центрального банка РФ; сравнительный анализ индикаторов банковской системы в разрезе федеральных округов выявил значительную монополизацию, в частности более $90 \%$ всех активов сосредоточены в банках, зарегистрированных на территории ЦФО; группировка субъектов РФ на основе показателей состояния банковской системы позволила выделить две группы, при этом в первую группу вошли крупные регионы с развитой экономикой; оценка влияния факторов на прибыльность банков показала, что в первой группе субъектов на эффективность кредитных организаций влияет объем выданных кредитов населению, тогда как во второй группе основное воздействие оказывают депозиты предприятий. Полученные результаты будут полезны исследователям в области рынка капитала и банковского сектора, а также служащим кредитных организаций при формировании стратегии развития банков.

Ключевые слова: кредитные организации, коммерческие банки, регионы России, пространственная экономика, эффективность деятельности, факторы, кластерный анализ, регрессионный анализ.

\section{Введение}

Состояние банковской системы во многом влияет на экономическую обстановку в стране, по этой причине, в условиях регулярных финансовых кризисов в России, на первое место выходит изучение устойчивости и адаптивности банковской системы к быстроменяющимся условиям турбулентной экономики. Особенно важно оценка текущего состояния и возможного (вероятного) положения региональных банковских систем при возникновении кризисов. В связи с этим считаем, что тема настоящей статьи является актуальной в период экономического спада, продолжающегося в России с 2014 года.

Обращаясь к теме влияния внутрирегиональных факторов на эффективность деятельности 
кредитных организаций находим публикации следующих авторов заслуживающих внимание Абу-Алроп Д.Х.А. [1], Антюфьев А. Г. [2], Гайрабекова М. Х. [3], Гайсин Р. С. [4], Дасковский В. Б. [5], Заяц И. Ю. [6], Зоидов К. Х. [7], Перегудова Т.А. [9], Сайдашева В.А. [10], Третьякова О.Г. [11]. В указанных работах в качестве индикатора характеризующего результат функционирования кредитных организаций используется сведения, содержащиеся в разделе «финансы» статистического ежегодника «Регионы России. Социальноэкономические показатели». По нашему мнению приводимые в данном издании сведения не в полной мере раскрывают особенности регионального банковского ландшафта, по этой причине в настоявшем исследовании будут использованы сведения Центрального банка РФ. Таким образом, система показателей будет состоять из 9 индикаторов приведенных на рисунке 1 .

Формирование матрицы данных проводимого исследования основано на официальных данных Центрального Банка РФ (Статистический бюллетень Банка России. № 12. 2020.Режим доступа: https://cbr.ru/statistics/bbs/ statisticheskiy-byulleten-banka-rossii/), а также сведениях предоставляемых Росстаном (Регионы России. Социально-экономические показатели. 2020.- Режим доступа: https://rosstat.gov. ru/folder/210/document/13204).

Опираясь на данные указанных источников, проведем анализ динамики основных индикаторов банковского сектора, а также вариационный анализ состояния кредитный организаций в регионах России.

\section{Результаты исследования}

Первым делом обратимся к данным формируемым Росстатом и проанализируем динамику основных индикаторов банковской системы в России (таблица 1).

Согласно данным приведенным в таблице 1, наблюдается планомерное снижение численности кредитных организаций, так в отчетном году по сравнению с 2010 г. значение снизилось на 297 единицы или на 25,2\%, но если сравнивать текущее положение с 1996 годом, когда наблюдалось максимальное количество банков в России (2601 ед.), то величина снижения становится колоссальной на 1720 ед. или на 66,1\%. Очевидно сложившаяся траектория связана со становлением денежно-кредитной системой, конкурентной борьбой на рынке капиталов и ужесточением надзора со стороны Центрально Банка РФ.

Приведенные в таблице 1 сведения наглядно иллюстрируют рост значений показателей привлечения и размещения капитала кредитными организациями, к примеру, в 2019 г. относительно 2018 г. вклады физических лиц увеличились на 10\%, тогда как относительно 2010 года выросли в 3,8 раза. Аналогичным образом ведут себя все остальные показатели.

Стоит также указать на значительное снижение за период 2010-2019 гг. ставки по кредитам, на 2,07 процентных пункта, что является следствием конкурентной борьбы на рынке капиталов, а также адаптацией банковской системы к условиям макросреды, а именно - стагнации экономики. Несмотря на неблагоприятную экономическую обстановку в стране, давление

Результат (следствие)

- Общий объем прибыли (+) / убытков (-), полученных действующими кредитными организациями (Y), млн руб.*

Факторы (причины)

- Удельный вес действующих кредитных организаций, имевших убытки (Z1), \%*

- Депозиты юридических лиц (Z2), млн руб.*

- Вклады (депозиты) и другие привлеченные средства физических лиц (Z3), млн руб.*

- Объем кредитов, предоставленных предприятиям обрабатывающих производств (Z4), $\%$ от общего объема выданных средств**

- Объем кредитов, предоставленных предприятиям оптовой и розничной торговли (Z5), \% от общего объема выданных средств**

- Объем кредитов предоставленных физическим лицам (Z6), млн руб.**

- Валовой региональный продукт на душу населения (X1), тыс. руб.***

- Инвестиции в основной капитал на душу населения (X2), тыс. руб.***

Рисунок 1. Система индикаторов региональной банковской системы (Примечания: "данные на 01.12.2020; ** октябрь 2020 года; *** сведения за 2018 г.) 
Таблица 1. Динамика основных показателей банковского сектора России, млрд. руб. *

\begin{tabular}{|l|c|c|c|c|c|c|c|}
\hline \multicolumn{1}{|c|}{ Показатели } & 2010 & 2015 & 2016 & 2017 & 2018 & 2019 & $\begin{array}{c}\text { К-т роста (сни- } \\
\text { жения) 2019 г. } \\
\text { к 2018 г. }\end{array}$ \\
\hline $\begin{array}{l}\text { Число кредитных организаций, зареги- } \\
\text { стрированных на территории, ед. }\end{array}$ & 1178 & 1049 & 1021 & 975 & 923 & 881 & 0,95 \\
\hline $\begin{array}{l}\text { Вложения кредитных организаций в } \\
\text { долговые обязательства }\end{array}$ & 3379 & 7651 & 9616 & 9366 & 9948 & 10857 & 1,09 \\
\hline $\begin{array}{l}\text { Депозиты, кредиты и прочие привле- } \\
\text { ченные кредитными организациями } \\
\text { средства }\end{array}$ & 16159 & 49545 & 49412 & 51514 & 53514 & 59782 & 1,12 \\
\hline $\begin{array}{l}\text { Вклады (депозиты) физических лиц в } \\
\text { кредитных организациях }\end{array}$ & 7485 & 23219 & 24200 & 25119 & 25987 & 28460 & 1,10 \\
\hline $\begin{array}{l}\text { Кредиты, депозиты и прочие размещен- } \\
\text { ные средсва, предоставленные органи- } \\
\text { зациям, физическим лицами и кредит- } \\
\text { ным организациям }\end{array}$ & 19180 & 54263 & 52816 & 54330 & 55810 & 62302 & 1,12 \\
\hline $\begin{array}{l}\text { Процентные ставки по кредитам, \% } \\
\text { Процентные ставки по депозитам, \% }\end{array}$ & 6,01 & 15,820 & 6,97 & 5,86 & 5,36 & 5,40 & Х \\
\hline $\begin{array}{l}\text { Общий объем прибыли, полученных } \\
\text { действующими кредитными организа- } \\
\text { циями }\end{array}$ & 573 & 192 & 930 & 790 & 1345 & 2037 & 1,51 \\
\hline
\end{tabular}

* составлено авторами по материалам издания «Российский статистический ежегодник»

со стороны стран еврозоны, показатели прибыльности банков только увеличиваются, так за 2018-2019 гг. рост составил 51\%, таким образом можно признать банковскую систему эффективной (с позиции банковского бизнеса) и стресоустойчивой.

Далее перейдем к рассмотрению особенностей развития банковской системы в региональном разрезе, для этого обратимся к таблице 2.

Ожидаемый результат получен по ЦФО, так на субъекты этого региона (Москва и Московская обл.) приходится наибольший объем прибыли (90,6\% от всей прибыли). Аналогичную картину мы наблюдаем по депозитам юридических лиц $(82,0 \%)$ и вкладам физических лиц (50,3\%). Примечательным является факт самого низкого значения кредитов предоставленных предприятиям обрабатывающих производств $7,1 \%$, несмотря на ведущую роль данной отрасли в экономики страны. Объясняется эта закономерность тем, что в ЦФО наибольший удельный вес (более 65\%) приходится на категорию «прочие отрасли», но при этом в статистическом сборнике не расшифровывается ее содержание.

Стоит обратить внимание на высокий процент кредитных организаций получивших убытки, так ЦФО - 28,0\%, ЮФО - 27,3\%, С-ЗФО $27,0 \%$, ПФО - 24,6\%. Высокое значение по ЮФО объясняется низким уровнем экономического развития субъектов входящих в состав региона, а следовательно низким уровнем жизни населения и деловой активности предприятий. На значения в трех других федеральных округах повлияла высокая конкуренция на рынке капи-

Таблиц̧а 2. Вариация индикаторов региональной банковской системы *

\begin{tabular}{|l|c|c|c|c|c|c|c|c|c|}
\hline Субъекты РФ & $\mathrm{Y}$ & $\mathrm{Z} 1$ & $\mathrm{Z} 2$ & $\mathrm{Z3}$ & $\mathrm{Z} 4$ & $\mathrm{Z} 5$ & $\mathrm{Z} 6$ & $\mathrm{X} 1$ & $\mathrm{X} 2$ \\
\hline РФ & 1300260,9 & 26,0 & 20581 & 32700 & 12,2 & 13,4 & 1564,4 & 33,2 & 131,6 \\
\hline ЦФО & 1177825,1 & 28,0 & 16868 & 16446 & 7,1 & 11,1 & 507,4 & 43,7 & 143,7 \\
\hline С-ЗФО & 78637,6 & 27,0 & 961 & 3880 & 21,2 & 26,0 & 190,2 & 36,2 & 144,0 \\
\hline ЮФО & 10716,2 & 27,3 & 230 & 2029 & 33,4 & 31,5 & 130,2 & 28,5 & 80,1 \\
\hline С-КФО & 79,2 & 12,5 & 44 & 487 & 16,1 & 19,5 & 40,5 & 23,3 & 61,7 \\
\hline ПФО & 9143,9 & 24,6 & 1053 & 4086 & 37,1 & 17,7 & 277,3 & 26,7 & 91,7 \\
\hline УФО & 12971,0 & 13,0 & 716 & 2281 & 35,7 & 6,9 & 152,1 & 35,0 & 235,6 \\
\hline СФО & 5750,8 & 19,0 & 479 & 2138 & 18,1 & 21,8 & 176,2 & 25,6 & 104,4 \\
\hline ДФО & 5137,2 & 20,0 & 231 & 1354 & 9,3 & 17,2 & 90,5 & 35,5 & 192,7 \\
\hline
\end{tabular}

* для наполнения таблицы использованы сведения Центрального Банка РФ и Росстата 
талов и стагнация в экономике.

Далее перейдем к оценке уровню дифференциации субъектов РФ по уровню развитости банковского сектора, для этого проведем кластерный анализ, используя индикаторы Z1-Z6. При этом в качестве кластер-процедуры используем древовидную кластеризацию, в качестве правила объединения субъектов РФ в отдельные группы использовали метод Варда (Уорда), мерой расстояния между группами будет Евклидова метрика. Стоит отметить, что при проведении процедуры из исходной совокупности были удалены г. Москва, г. Санкт-Петербург, Московская область, так как данные объекты имеют высокий уровень рассматриваемых показателей, тем самым выбиваются из общей массы, т.е. являются «выбросами» (рисунок 2).

Данные представленные на рисунке 2 показывают, что исходная совокупность разделилась на две группы.

В первую группу вошли субъекты РФ с высо- кими значениями индикаторов, при этом средний удельный вес убыточных банков в этом кластере минимальный. Также стоит отметить, что в эту подсовокупность вошли субъекты из ПФО, УФО и СФО, т.е. наиболее экономически развитые регионы.

Для оценки уровня концентрации и конкурентоспособности в таблицу 3 были добавлены данные по трем субъектам РФ, это г. Москва, г. Санкт-Петербург, Московская область. Средние значения по данной группе («выбросы») наивысшие, что указывает на сосредоточение капиталов именно в этих трех субъектах и наличии монополий в банковском секторе.

Очевидно, что в сложившихся подсовокупностях субъектов РФ на эффективность функционирования региональной банковской системы оказывают влияние (воздействие) различные факторы, поэтому оценим значения коэффициентов корреляции отдельно для каждого кластера [12] (рисунок 3).

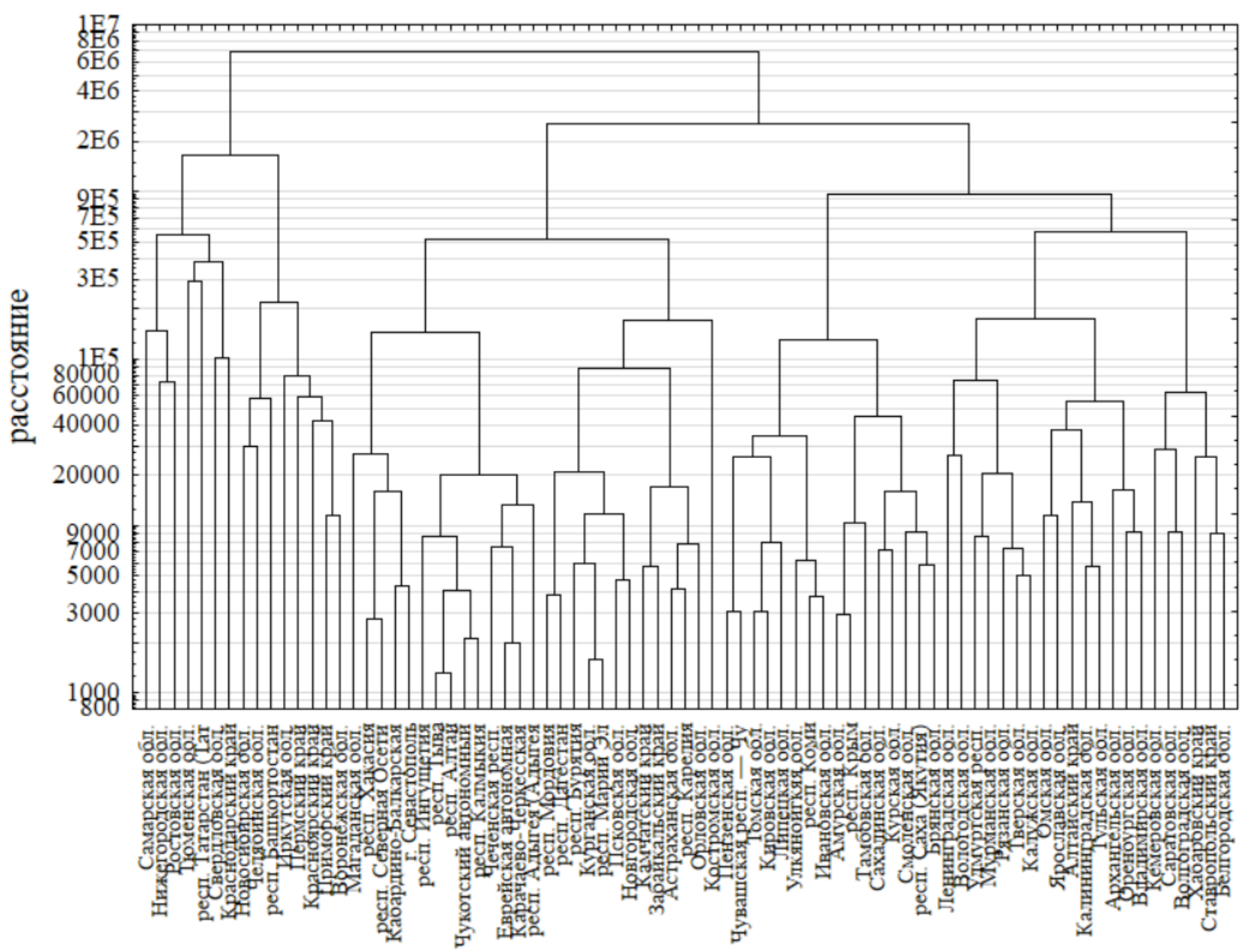

Рисунок 2. Диаграмма объединения субъектов РФ в группы на основе индикаторов состояния региональной банковской системы

(Источник: рассчитано в пакете STATISTICA, на основе данных Центрального Банка РФ) 
Таблица 3. Внутригрупповые средние, для двух групп субъектов РФ сформированных на основе индикаторов состояния региональной банковской системы

\begin{tabular}{|c|c|c|c|}
\hline \multirow{2}{*}{ Показатели } & 1 группа & 2 группа & Выбросы * \\
\cline { 2 - 4 } & 15 & 64 & 416146 \\
\hline $\mathrm{Y}$ & 2077 & 323 & 29,7 \\
\hline $\mathrm{Z} 1$ & 14,2 & 17,0 & 5714593 \\
\hline $\mathrm{Z} 2$ & 158832 & 15845 & 5396376 \\
\hline $\mathrm{Z} 4$ & 552952 & 128384 & 25,3 \\
\hline $\mathrm{Z} 5$ & 33,7 & 25,8 & 146718 \\
\hline $\mathrm{Z} 6$ & 17,9 & 20,3 & 52697 \\
\hline $\mathrm{X} 1$ & 35700 & 9200 & 163566 \\
\hline
\end{tabular}

*г. Москва, г. Санкт-Петербург, Московская область

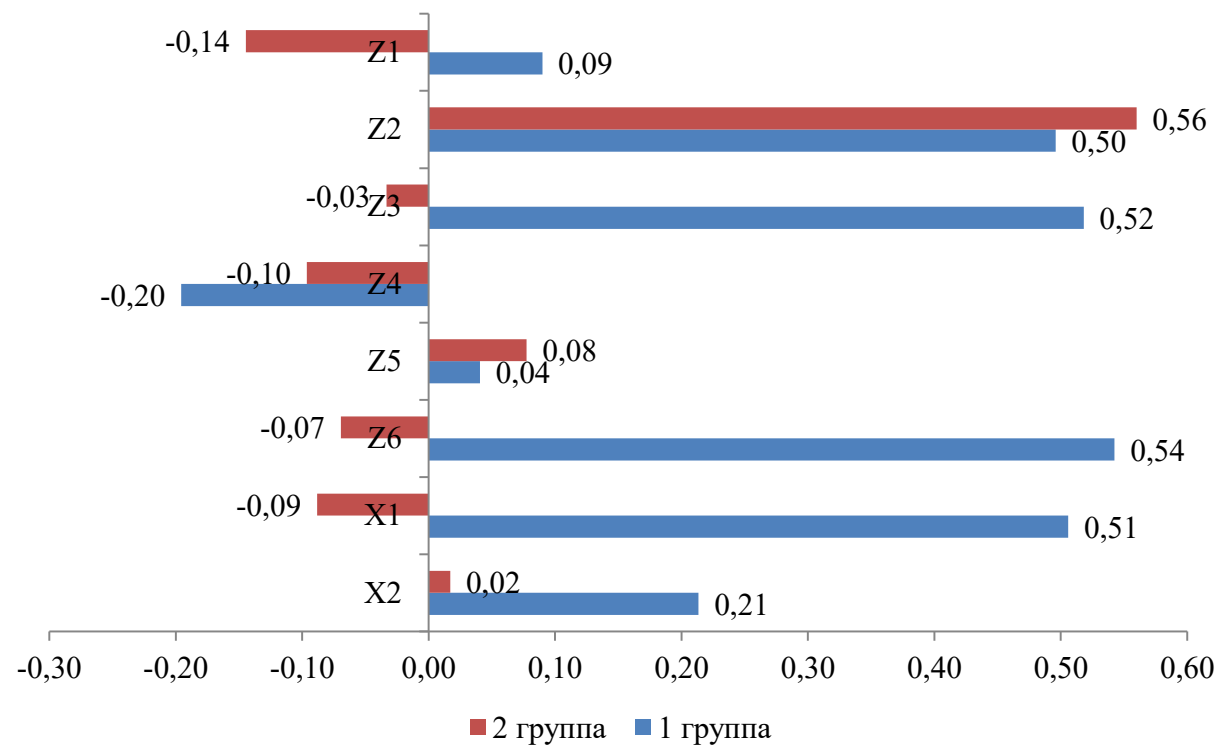

Рисунок 3. Значения коэффициентов корреляции для двух групп субъектов РФ сформированных на основе индикаторов состояния региональной банковской системы (Источник: рассчитано в пакете STATISTICA, на основе данных Центрального Банка РФ)

Приведенные на рисунке 3 значения коэффициента указывают, что в каждой группе сложились свои факторы, которые оказывают влияние на финансовый результата банков, так в первой группе наибольшее влияние на Ү оказывает Z6 (коэффициент равен 0,54), тогда как во втором это фактор Z2 (коэффициент равен 0,56). Поэтому для построения эконометрических моделей отражающих причинно-следственную связь в региональном банковском секторе воспользуемся указанными факторами:

- Группа № 1: $\mathrm{Y}^{\prime}=-4204,01+0,17 \times \mathrm{Z6}, \mathrm{F}($ факт $)$ $=5,30$;
- Группа № 1: Y’ = 142,83 + 0,013×Z2, F(факт) $=17,77$.

Приведенные модели получены статистически значимы по $\mathrm{t}$-статистике Стьюдента и F-статистике Фишера, при этом коэффициент корреляции указывает на высокую связь между результативной переменной и факторами.

Интерпретация оцененных коэффициентов регрессионных уравнений заключается в следующем:

1) по первой группе субъектов РФ увеличение на 1 млн. рублей объемов выданных кредитов населению (физическим лицам), уровень 
прибыли банков в среднем увеличится на 0,17 млн. руб., при условии неизменности остальных факторов.

2) по второй группе субъектов РФ рост на 1 млн. рублей депозитов юридических лиц, ведет к росту прибыли кредитных организаций в среднем на 0,013 млн. руб., при условии постоянства прочих факторов.

Приведенные выше модели удовлетворяют всем формальным требованиям эконометрической методологии, поэтому используем их для имитационного моделирования. Так как в России в 2020 г. (впрочем, как и во всем мире) наблюдается кризис вызванный пандемией вируса Covid-19, в качестве предполагаемых (вероятных) состояний факторов Z2 и Z6 используем текущие средние значения, по группе сниженные на 10\%, 20\% и 30\% (таблица 4).

Приведенные в таблице 4 прогнозы наглядно показывают, что снижение как объемов выданных кредитов населению (первая группа субъектов РФ), так и привлеченных депозитов предпринимателей (вторая группа субъектов РФ) даже на $10 \%$ приводит к возможным убыткам (нижняя доверительная граница прогноза). Таким образом, можем сделать вывод о незначительном приделе стресс-прочности региональной банковской системы в России.

\section{Выводы}

Проведенный анализ влияния факторов на состояние региональной банковской системы, позволяет сделать ряд заключений и выводов.

Во-первых, анализ в динамике основных показателей банковского сектора показало, что в России наблюдается снижение численности кредитных организаций, начиная с середины 1996 г., что обусловлено высокой конкуренци- ей на рынке капиталов и ужесточением надзора со стороны Центрального банка РФ. При этом в 2019 году относительно 2018 года наблюдается рост индикаторов, что косвенно свидетельствует об эффективности функционирования кредитных организаций.

Во-вторых, вариационный анализ индикаторов банковской системы в разрезе федеральных округов выявил значительную монополизацию, в частности подавляющее большинство всех активов сосредоточены в банках, зарегистрированных на территории ЦФО, а именно в г. Москве и Московской области. Данная закономерность негативным образом влияет на развитие региональной банковской системы.

В-третьих, кластеризация совокупности субъектов РФ на основе шести индикаторов состояния региональной банковской системы позволила выделить две группы, при этом в первую группу вошли крупные регионы с развитой экономикой, тогда как во вторую Регинины с минимальными значениями. Тем не менее, максимальные значения фиксируются в трех субъектах, это именно в г. Москва, г. Санкт-Петербург и Московская область. Что еще раз подчеркивает несовершенство банковской системы в России.

B-четвертых, изучение влияния факторов на результат функционирования кредитных организаций в регионах России показал, что первой группе субъектов на эффективность влияет объем выданных кредитов населению, тогда как во второй группе основное воздействие оказывают депозиты предприятий. Имитационное моделирование на основе эконометрических моделей позволили утверждать о фактическом достижении предела запаса прочности региональной банковской системы.

Таблица 4. Предполагаемые (вероятные) значения прибыли кредитных организаций, под влиянием кризиса вызванного пандемией вируса Covid-19, млн. руб.

\begin{tabular}{|c|c|c|c|c|c|}
\hline \multirow{2}{*}{ Группа } & \multirow{2}{*}{ Показатели } & \multirow{2}{*}{$\begin{array}{c}\text { Средние значения } \\
\text { по группе }\end{array}$} & \multicolumn{3}{|c|}{ Прогноз } \\
\hline & & & $-10 \%$ & $-20 \%$ & $-30 \%$ \\
\hline \multirow{4}{*}{1} & Z6 & 35700 & 32130 & 28560 & 24990 \\
\hline & $\mathrm{Y}$ & 2077 & 1226 & 623 & 20 \\
\hline & Ниж. дов. граница прогноза Y & - & -706 & -1613 & -2633 \\
\hline & Верх. дов. граница прогноза Y & - & 3158 & 2859 & 2672 \\
\hline \multirow{4}{*}{2} & $\mathrm{Z} 2$ & 15845 & 14261 & 12676 & 11092 \\
\hline & $\mathrm{Y}$ & 323 & 322 & 302 & 282 \\
\hline & Ниж. дов. граница прогноза Y & - & -7 & -29 & -52 \\
\hline & Верх. дов. граница прогноза Y & - & 650 & 633 & 616 \\
\hline
\end{tabular}




\section{Библиографический список}

1. Абу-Алроп Д.Х.А. Влияние финансовых рисков на результаты деятельности российских банков (2016-2017) // Современная наука: актуальные проблемы теории и практики. Серия: Экономика и право. 2020. № 3. С. 13-18.

2. Антюфьев А.Г., Табачный Е.М. Акторы и угрозы, оказывающие непосредственное влияние на экономическую безопасность инвестиционной деятельности коммерческих банков // Вестник науки и образования. 2018. T. 1. № 8 (44). С. 23-25.

3. Гайрабекова М.Х., Арсаханова 3.А. Эффективность функционирования финансовой системы региона: проблемы и перспективы // Московский экономический журнал. 2020. № 4. С. 64.

4. Гайсин Р.С., Быков Д. В. Статистическая оценка влияния финансово-экономических кризисов на состояние банковского сектора России // Экономический анализ: теория и практика. 2019. Т. 18. № 4 (487). С. $770-785$.

5. Дасковский В.Б., Киселев В.Б. Еще раз о несоответствии оценок эффективности инвестиций // Экономист. 2010. № 7. С. 78-92.

6. Заяц И. Ю. Факторы, оказывающие влияние на финансовую стабильность коммерческих банков // Экономика и бизнес: теория и практика. 2020. № 4-1 (62). С. 133-137.

7. Зоидов К.Х., Пономарева С.В., Серебрянский Д. И. Оценка и моделирование финансовой позиции кредитного учреждения // Региональные проблемы преобразования экономики. 2018. № 7 (93). С. 116-127.

8. Перегудова Т.А., Беляева А. А. Влияние факторов на формирование ресурсов банка // Globus. 2020. № 11 (57). C. 59-64.

9. Петров А.М. Внутреннее заимствование как механизм распределения денежных потоков в корпоративных системах // Экономический анализ: теория и практика. 2012 . № 14 (269). С. 8-15.

10. Сайдашева В.А., Шарафутдинова Н.С., Валеева Ю.С. Анализ факторов, влияющих на объем прибыли коммерческого банка // Научное обозрение: теория и практика. 2018. № 9. С. 6-11.

11. Третьякова О.Г., Чинаева Т.И. Статистический анализ финансового состояния банковского сектора // Статистика и Экономика. 2018. Т. 15. № 2. С. 20-29.

12. Эконометрика: учебник / В.Н. Афанасьев, Т. В. Лебедева, Т. В. Леушина, А. П.Цыпин.-Оренбург: ООО ИПК «Университет». 2012.-402 с.

13. Chernysheva N.A., Perskaya V. V., Petrov A. M., Bakulina A.A. GREEN ENERGY FOR BELT AND ROAD INITIATIVE: ECONOMIC ASPECTS TODAY AND IN THE FUTURE / International Journal of Energy Economics and Policy. 2019. T. 9. № 5. C. 178-185.

14. Kevorkova Z.A., Petrov A. M., Savina N. V. TOWARDS LIABILITIES OF CORPORATE SYSTEMS / International Journal of Civil Engineering and Technology. 2019. T. 10. № 2. C. 1582-1593.

15. Petrov A.M., NikiforovaE.V., Kiseleva N.P., GrishkinaS.N., Lihtarova O.V. CREATION OF THE REPORTING ON SUSTAINABLE DEVELOPMENT OF COMPANIES BASED ON SOCIOECONOMIC MEASUREMENT STATISTICS / International Journal of Recent Technology and Engineering. 2019. T. 8. № 2. C. 4005-4012.

16. SotnikovaL.V., PolenovaS.N., MislavskayaN.A., PetrovA.M., BasovaM.M. SUSTAINABLE DEVELOPMENT, MACRO AND MICRO LEVEL: RUSSIAN AND FOREIGN MODEL / International Journal of Recent Technology and Engineering. 2019. T. 8. № 2. C. 4524-4532.

17. Kosolapova M.V., Muravitskaya N.K., TolmachevM.N., Melnikova L.A., PetrovA.M. TECHNOLOGY FOR SOLVING THE PROBLEMS RELATED TO THE IMPLEMENTATION OF THE CONCEPT OF PRESERVING CAPITAL IN ACCOUNTING AND STATISTICS / International Journal of Recent Technology and Engineering. 2019. T. 8. № 3. C. 789-792.

18. Kosolapova M.V., PetrovA.M., YshanovI.G., Muravitskaya N.K., NurmuhamedovaH.S. THE ECONOMIC SIGNIFICANCE OF STATISTICAL RESEARCH ACTIVITIES OF REPRESENTATIVE OFFICES OF COMPANIES ABROAD / International Journal of Innovative Technology and Exploring Engineering. 2019. T. 8. № 10. C. 27132722.

19. Petrov A.M., Yurasova I. O., Putihin Y.E., Poluleh M. V., Erohina V. N. ACCOUNTANT MODELING TECHNOLOGY AND STATISTICS IN THE CONTEXT OF THE NEW EDUCATIONAL CONCEPT / International Journal of Innovative Technology and Exploring Engineering. 2019. T. 8. № 12. C. 3214-3217.

20. Petrov A.M., Kiseleva N.P., KevorkovaZ.A., MelnikovaL.A., YshanovI.G. PRESENT DEVELOPMENT PRACTICES FOR TAX, FINANCIAL AND STATISTICAL REPORTING IN THE RUSSIAN FEDERATION / International Journal of Innovative Technology and Exploring Engineering. 2019. T. 8. № 12. C. 3538-3542. 
21. Karpova T.P., Petrov A.M., Antonova O.V. DIRECTIONS OF ACCOUNTING DEVELOPMENT IN THE CONDITIONS OF DIGITALIZATION / Journal of Advanced Research in Dynamical and Control Systems. 2018. T. 10. № 7 Special Issue. C. $117-125$.

22. Lymar M.P., Kevorkova Z.A., Petrov A. M. THE CONVERGENCE OF NATIONAL AND INTERNATIONAL ACCOUNTING STANDARDS: CHINESE EXPERIENCE / International Journal of Civil Engineering and Technology. 2018. T. 9. № 13. C. $82-94$. 